\title{
Ekonomik ve Teknolojik Faktörlerin Yüksek Ofis Yapılarının Ortaya Çıkışı ve Gelişimi Üzerindeki Etkisi
}

\author{
Görkem ARSLAN KILINÇ ${ }^{1 *}$, Ayşin SEV ${ }^{1}$
}

Öz

Yüksek ofis yapıları günümüz kentlerinin sıkça rastlanan birer ögesidir. Bu yapı tipolojisinin ortaya çıkışı, mimari ve strüktürel gelişimi üzerinde etkili temel faktörler ise sosyo-ekonomik ve teknolojik faktörlerdir. Daha yüksek kar getirisi sağlayacak yapılar ve mekanlar elde etme isteği 19. ve 20. yy boyunca yüksek ofis yapılarının mimarilerinin ve strüktürel sistemlerinin tasarımına yön vermiş, teknolojik ilerlemeler ise yüksek ofis yapılarındaki bu değişimi/gelişimi mümkün kılmıştır. Ekonomik faktörlerin yüksek ofis yapıları üzerindeki etkisi biçim değiştirmiş olsa da, günümüzde de sürmektedir. Bulunduğu ülkeye ve yatırımcısına daha fazla prestij ve gelir sağlaması hedeflenenrek tasarlanan yüksek yapılar her geçen gün daha yenilikçi teknolojileri benimsemekte olup, daha yükseğe ulaşmaya çalışmaktadır. 19. yy sonlarında ve 20. yy başlarında bir tasarım problemi oluşturmayan fakat günümüzde yüksek ofis yapılarının mimari ve strüktürel gelişimine yön veren bir diğer etmen ise enerjinin etkin kullanımıdır. Bu çalışma kapsamında 19 yy'den 21. yy'ye yüksek ofis yapılarının ortaya çıkışı ve gelişimi ekonomik ve teknolojik faktörlerin etkisi ekseninde incelenmiş ve değerlendirilmeler ortaya konulmuştur.

Anahtar Kelimeler: Yüksek ofis yapıları, mimari gelişim, strüktürel gelişim, ekonomik faktörler, teknolojik faktörler

\section{The Effects of Economic and Technologic Factors on the Emergence and Development of Tall Office Buildings}

\begin{abstract}
One of the most common pillars of the cities are tall office buildings. Economic and technologic factors are the main factors which effects architectural and structural development of the tall office buildings. The desire to obtain higher return on profits from tall office buildings has effected the architectural and structural design of tall office buildings, and technological advances have led to this change. Even though, effect of economic factors shapes design of tall office buildings in a different way, that is still an effective factor on design process. Tall buildings are designed to provide more prestige and income to its investors. Therefore, as time goes by they are adopted more innovative technologies and getting higher. Another factor that did not pose a design problem in the late 19th century and early 20th century, but effects today the architectural and structural development of tall office buildings is the efficient use of energy. Within the scope of this study, the emergence and development of high-rise office buildings from the 19th century to the 21st century were examined and evaluated in the axis of the impact of economic and technological factors.
\end{abstract}

Keywords: Tall office buildings, architectural development, structural development, economic factors, technologic factors

\footnotetext{
${ }^{1}$ Mimar Sinan Güzel Sanatlar Üniversitesi, Mimarlık Anabilim Dalı, Yapı Bilgisi Bilim Dalı

* Illgili yazar/Corresponding author: gorkem.arslan@msgsu.edu.tr 


\section{GíRiş}

Toplumsal kalkınma sürecinde bilim, teknoloji ve ekonomi birbirleriyle etkileşim içinde gelişmiştir. Üretim teknolojilerindeki gelişmeler, toplumların sosyo-ekonomik yapılarında köklü değişikliklere neden olmuş, buna paralel olarak yeni yapılanmalar yaşayan, değişen ve gelişen toplumlar intiyaçları doğrultusunda yapılı çevreyi de biçimlendirmiştir.

Toplumların sosyo-ekonomik gelişim ve değişimine paralel olarak ortaya çıkan en tipik yapı tipolojilerinden biri yüksek (ofis) yapılarıdır. Bu yapı tipolojisinin gelişimsel tarihi incelendiğinde öncelikle ekonomik kaygıların ve kar güdüsünün etkileri açıkça görülmektedir. Örneğin, birçok yüksek yapının tasarımcısı Cass Gilbert, 1900 yılında Woolworth Binası'nın tasarımını gerçekleştirmeden 10 yıl önce, yüksek yapıları "arsaların para üretmesini sağlayan makineler" olarak tanımlamıştır. Yine 19. yüzyıl sonlarında önemli bir gayrimenkul uzmanı olan George Hill, The Architectural Record dergisinde ofis binalarının en önemli hedefinin yatırımcısına yüksek getiri sağlamak olduğunu, yüksek getiri hedefinin ise belirlenen parsel üzerindeki kiralanabilir alanlarının niceliksel değerinin arttırılması ve bu kiralanabilir alanların doğal ışığa sahip olmasının sağlanmasıyla gerçekleştirilebileceğini ifade etmiştir (Willis, 1995, s. 24-34).

Buradan hareketle, bu çalışmada yüksek ofis yapılarının ortaya çıkma ve gelişme nedenleri, bu gelişim sürecinde sosyo-ekonomik ve teknolojik faktörlerin mimari ve strüktür tasarımındaki etkisi araştırılarak ortaya konmuştur.

\section{YÜKSEK OFIS YAPILARININ GELIŞIMI}

18. yy sonunda İngiltere'de başlayarak kısa sürede Avrupa ve Kuzey Amerika'da etkili olan Endüstri Devrimi ile oluşmaya başlayan sermaye birikimi özel bankaların ve sigorta şirketlerinin kurulmasını sağlamıştır. Bu yeni oluşum profesyonel çalışanların istihdam edileceği mekanların sivil mimarlıktan ayrılarak özelleşmesini başka bir deyişle ofis binası tipolojisinin oluşmasını sağlamıştır (Hascher, Jeska, \& Klauck, 2002, s. 15).

19. yy'nin ikinci yarısında endüstriyel, ticari alanda gerçekleşen hızlı genişleme, raylı ulaşım sistemlerinin de gelişmesiyle kent merkezlerinde bankaların, sigorta şirketlerinin ve fabrikaların sayısı artmaya başlamıştır. Hızlı endüstrileşmeye ek olarak, teknolojinin sanayide kullanılması istihdamı arttırmıştır. Bu durum kent merkezlerinde çalışma alanlarına olan gereksinimi artırmıştır. Bu talebe bir cevap olarak ofis yapıları yükselmeye başlamıştır. Tüm bu faktörlerin etkisiyle yüksek (ofis) yapıların ilk örnekleri Amerika'da önemli finans merkezleri haline gelen Chicago ve New York kentlerinde inşa edilmiştir (Sev, 2015, s. 3-13).

Ekonomik büyümenin yanı sıra, teknolojik yenilikler de yüksek ofis yapılarının gelişimi üzerinde etkili olmuştur. 1880'lerde çelik profillerin ve hidrolik asansörlerin kullanılmaya başlanması rijit çelik çerçeveli yapıların çok katı tasarımına imkan tanımıştır. Ayrıca telefon, yapay aydınlatma ve havalandırma, bilgisayar sistemlerinin gelişimi gibi diğer teknolojik ilerlemeler ile ofis kavramı kalıcılık kazanmış ve genişlemiştir (Willis, 1995).

Bu bölümde ekonomik ve teknolojik faktörlerin yüksek ofis yapılarının gelişimi üzerindeki etkileri, mimari ve strüktürel gelişim olmak üzere iki alt başlık halinde ele alınacaktır. 


\subsection{Ekonomik ve teknolojik faktörlerin mimari gelişime etkisi}

19. yy'de büyük şirketler kurulmaya başlamış, bu şirketler genel müdürlük binalarını kent merkezlerinde konumlandırmak istemiştir (Short, 2012, s. 6-7). Bu gelişme şirketlerin yazı, evrak ve iletişim işleri ile ilgilenecek "beyaz yakalı" olarak isimlendirilen bir çalışanlar topluluğunun şirketlerin genel müdürlüklerinde görevlendirilmeleri ile sonuçlanmıştır. Yeni bir kavram olarak ortaya çıkan "şirket genel merkezleri" ve bunları temsil eden çok katlı ofis yapıları aynı zamanda prestij unsuru haline gelmiştir. Böylece "ofisler" artık yeni bir boyut kazanmaya başlamışlardır (Piotrowski \& Rogers, 1999, s. 810).

Yoğun kent merkezlerinde, büyük şirketlerin çok sayıdaki beyaz yakalı çalışanının barındırılması gereken bu sosyo-ekonomik ortamda, düşey ulaşım sistemlerinin de geliştirilmiş olmasıyla (Elisha Otis tarafından tasarlanan ilk yolcu asansörü, yapımı 1857 yılında tamamlanan Haughwout Binasında kullanılmıştır (Moon, 2005).) Yüksek Yapılar ve Kentsel Yerleşimler Konseyi (CTBUH) tarafından ilk yüksek yapı olarak kabul edilen Home Insurance Binası (1885, Chicago) yapılmıştır (Moon, 2005). William Le Baron Jenney tarafından tasarlanan Home Insurance Binası 10 katlı olup, 1890 yılında iki kat daha eklenmesiyle 12 kata ulaşmıştır (Sev, 2015). Yapıda ofis mekanları doğal ışık gereksinimi sebebiyle pencere kenarları boyunca konumlandırılırken, düşey sirkülasyon elemanları, ıslak hacimler ve servis alanları yapının uzun kenarında yer almaktadır. Yatay sirkülasyon elemanı olan koridorlar ise yapının uzun kenarına paralel olarak yapı boyunca devam eder. Yapıda geleneksel bir diğer ismiyle hücresel ofis sistemi benimsenmiştir (Şekil 1).

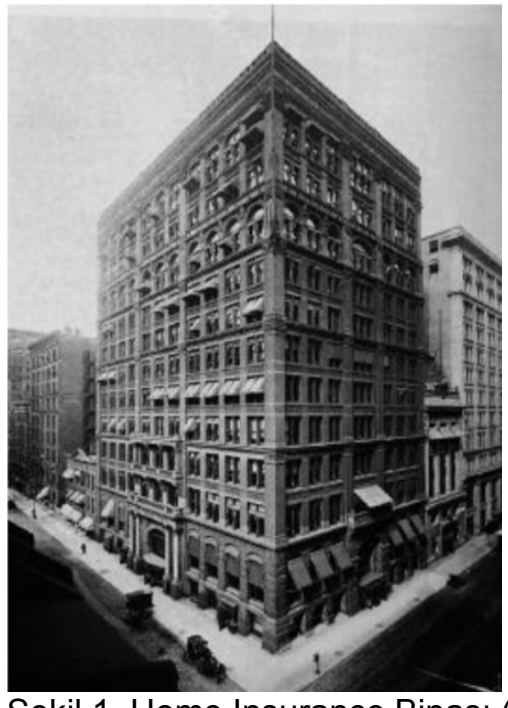

Şekil 1. Home Insurance Binası (solda) ve tipik kat planı (sağda) Chicago, 1885 (Larson \& Geraniotis, 1987, s. 39).

19. yy'nin ikinci yarısında yüksek ofis yapılarında kiralanabilir alanların niteliği-niceliği ve kar getirisi arasındaki ilişkileri araştıran bilimsel çalışmalar başlamıştır. Bu dönemde, kiralanacak mekanların birim alan fiyatları konusunda yapılan araştırmalar çekirdekcephe arasındaki uzaklığın 8,5 m'den fazla olduğu durumlarda doğal ışık seviyesinin azalmasına bağlı olarak kira gelirlerinin düştüğünü göstermiştir. Doğal ışık seviyesi düşük mekanların düşük ücretlere pazarlanıyor olması "verimli kat derinliği" kavramının doğmasına yol açmıştır. Çekirdek-cephe arasındaki en kısa mesafe olarak tanımlanan "plan derinliğinin" yanısıra, yapıların plan biçimleri, tavan yükseklikleri, pencere biçim ve boyutları da ekonomik kaygılarla tasarlanmıştır. Mekan içine daha fazla doğal ışık 
alınabilmesi için tavan yükseklikleri ve pencereler mümkün olan en geniş ölçülerde biçimlendirilmiştir (Willis, 1995, s. 24-34)2.

Holabird \& Roche tarafından tasarımı yapılarak, 1895 yılında Chicago'da inşa edilen Old Colony Binası dönemin ofis yapılarının plan kurgusunu gözler önüne sermektedir. Old Colony Binası'nda tüm ofisler pencereden en fazla 8 metre uzaklıkta olacak şekilde düzenlenmiştir. 3 metre genişliğinde merkezi bir koridor etrafında küçük ofisler konumlandırılmıştır. Bu küçük ofisler üst rütbeli çalışanların ofislerine açılmaktadır (Şekil 2) (Url-1 2017). Yapıda bodrum kat depolama amaçlı kullanılırken; ilk kat lobi ve mağazalara ayrılmıştır. 2-17 katları ofisleri barındııı. Çatı katı ise makine dairesi olarak kullanılmıştır (Url-1, 2017). Old Colony Binası \%89 oranında kiralanabilir alana sahiptir. Döneminin teknolojik imkanları düşünüldüğünde \%89 kiralanabilir alana sahip Old Colony binası kiralanabilir alanlarının niceliğine verilen önemi açıkça göstermektedir (Url-5).
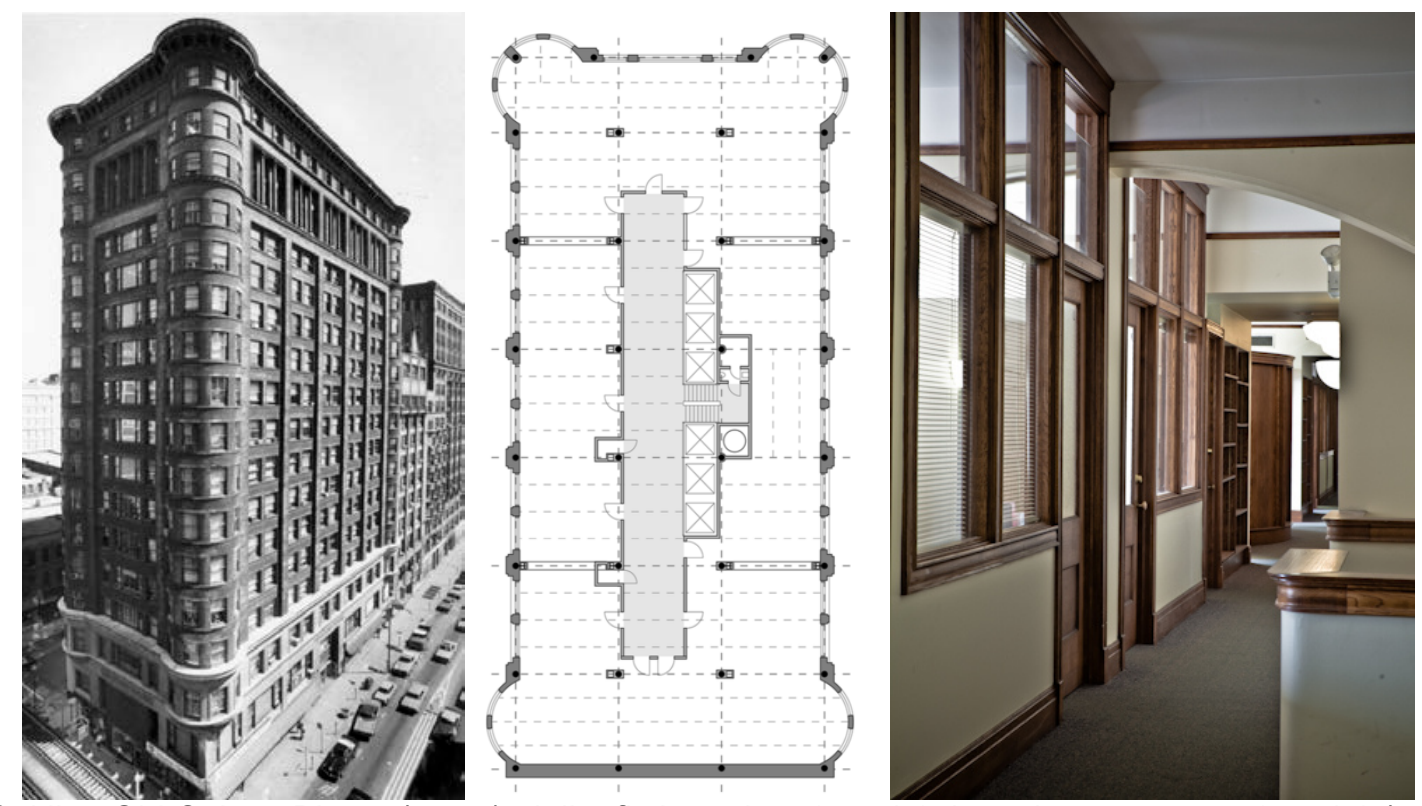

Şekil 2. Old Colony Binası (solda), tipik ofis katı planı (ortada), iç mekan görünüşü (sağda) (Url5) 1895, Chicago (Leslie, 2010, s. 244).

Yüksek ofis yapılarının formları üzerinde verimli kat alanı elde etme kaygısıyla birlikte etkili olan faktörlerden bir diğeri yapının inşa edileceği parselin biçimidir. New York'ta yüksek ofis yapılarının formları arsa geometrisinden kaynaklanan nedenlerle, Chicago'dan farklı şekilde gelişmiştir. Arsalar dikdörtgen biçimli olduğundan, asansörlerin yapı merkezinde toplandığı, 8-9 m plan derinliğine sahip ofislerden oluşan plan şemalarının hakim olduğu görülmektedir. Tasarımı Francis Hatch Kimball tarafından gerçekleştirilerek 1905 yılında inşa edilen Trinity Binası (Trinity Building) ve yine tasarımı Francis Hatch Kimball tarafından gerçekleştirilerek 1907 yılında inşa edilen A.B.D. Reality Binası (U.S. Reality Building) bu farklıığı en çarpıcı şekilde ortaya koyan iki örnektir (Şekil 3) (Trabucco, 2010, s.43).

\footnotetext{
${ }^{2}$ Doğal ışık sağlanması yüksek ofis yapılarının mimari gelişimi üzerinde önemli etkilere sahip olmuştur. Elektrik 19. yüzyılın sonlarında var olsa da, enkandesan lambalar ofis yapılarında verimli çalışma sağlanabilmesi için yeterli aydınlık seviyesini sağlayamamıştır. Bu sebeple 1940'larda floresan lambaların tanıtılmasına kadar ofislerde gerekli olan aydınlık seviyesi intiyacı doğal aydınlatma yöntemiyle giderilmek zorunda kalınmıştır (Willis, 1995, s. 24-34).
} 

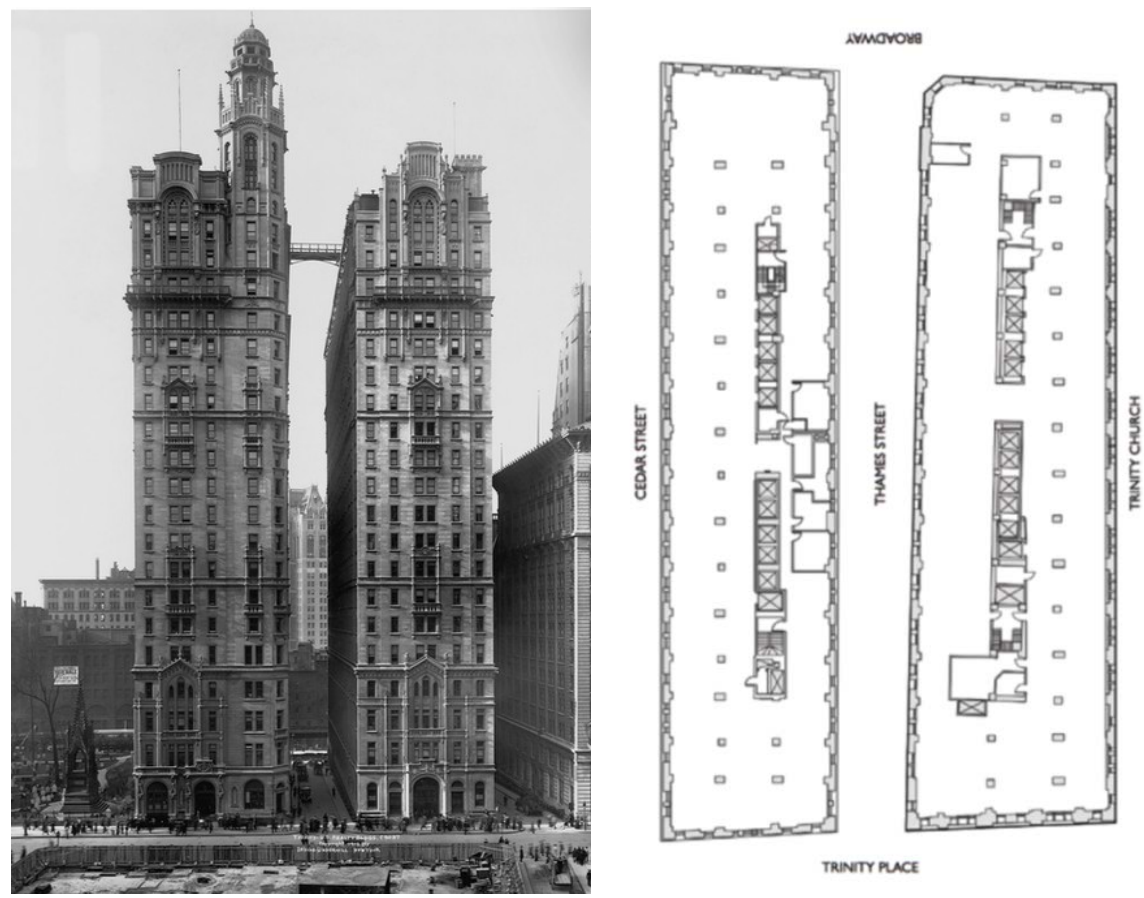

Şekil 3. Trinity ve A.B.D. Reality Binaları görünüsü (solda), planı (sağda) (New York, 1905-New York, 1907) (Willis, 1995, s. 41).

Chicago kentinde ise arsa planlarının kare veya kareye yakın olması sebebi ile kare planlı yüksek ofis yapıları yaygınlaşmıştır. Geniş arsalarda yapılan ve geniş kat planlarına sahip bu yapılarda ofislerin doğal ışık intiyacını karşılamak için merkezi avlular tasarlanmıştır. Hücresel ofisler ve düşey sirkülasyon elemanları ise plan kenarlarında konumlandırılmışlardır (Wood \& Salib, 2013; Trabucco, 2010). Şekil 4'de görülen Daniel Burnham tarafından tasarımı gerçekleştirilen Peoples Gas Company Binası bu yapılara örnek oluşturmaktadır.
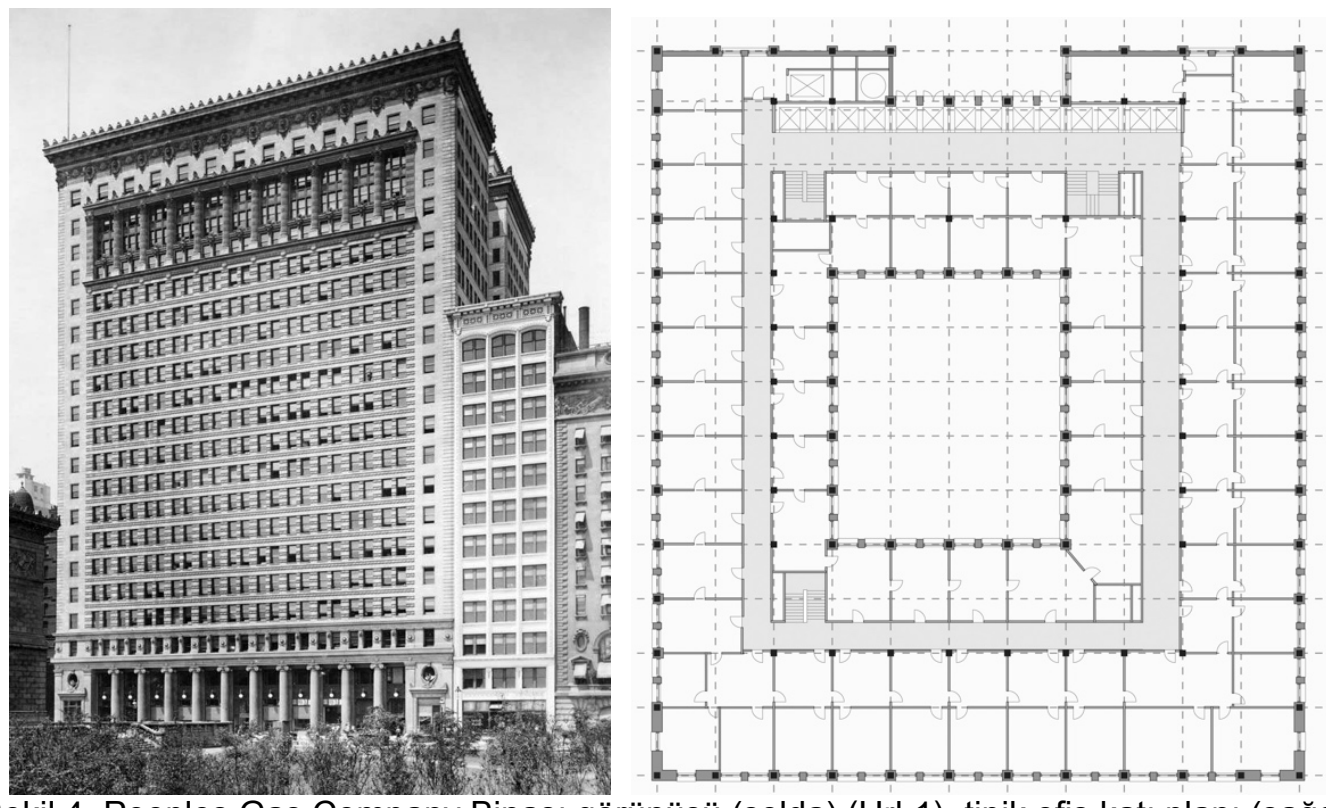

Şekil 4. Peoples Gas Company Binası görünüşü (solda) (Url-1), tipik ofis katı planı (sağda) (Chicago, 1911) (Willis, 1995, s. 60-62). 
Bu planlama yaklaşımı 1890'ların ortalarından 1910'lara kadar dikdörtgen forma sahip parsellerde yapılan yüksek ofis yapılarının çoğunda etkili olmuştur (Willis, 1995, s. 49$66)$.

20. yy'nin ilk çeyreğinde finansal kaygıların yüksek ofis yapılarının iç mekan kurgusu üzerindeki bir başka etkisi çalışma biçiminin rasyonelleştirilmesi fikrinin mimaride karşılık bulmasıyla gerçekleşmiştir. Yönetim bilimine ilgi duyan Amerikalı bir makine mühendisi olan Frederick W. Taylor 1911 yılında çalışmanın rasyonelleştirilmesine ilişkin fikirlerini "İşletmelerin Bilimsel Yönetimi" (The Principles of Scientific Management) isimli kitabında yayınlar. Taylorizmin üç ana ilkesi kısaca şu şekildedir;

- Bir işin en verimli şekilde yapılması için geleneksel yöntemler bırakılmalı; zaman ve hareket araştırmalarının yardımıyla yeni yöntemler geliştirilmelidir.

- Çalışanlar özendirilerek, yapılacak için etkin ve hızlı bir şekilde gerçekleştirilmesi sağlanmalıdır.

- Çalışma kurallarının ve yönteminin uygulama sürecindeki kontrolü tecrübeli ustabaşılar tarafından sağlanmalıdır. Kurallara uymayanlar cezalandırılmalıdır.

Taylorizm etkisiyle ofis katlarında, çalışma üniteleri geniş bir mekan içinde yan yana herhangi bir bölücü eleman kullanılmadan sıralandırılmaya başlamıştır. Frank Lloyd Wright'ın tasarımını gerçekleştirdiği New York'ta bulunan Larkin Sabun Fabrikası Yönetim Binası (1906), yüksek yapı olmasa da bu ofis yapılarının etkili bir örneğini oluşturmaktadır (Şekil 5) (Piotrowski \& Rogers, 1999, s. 8).
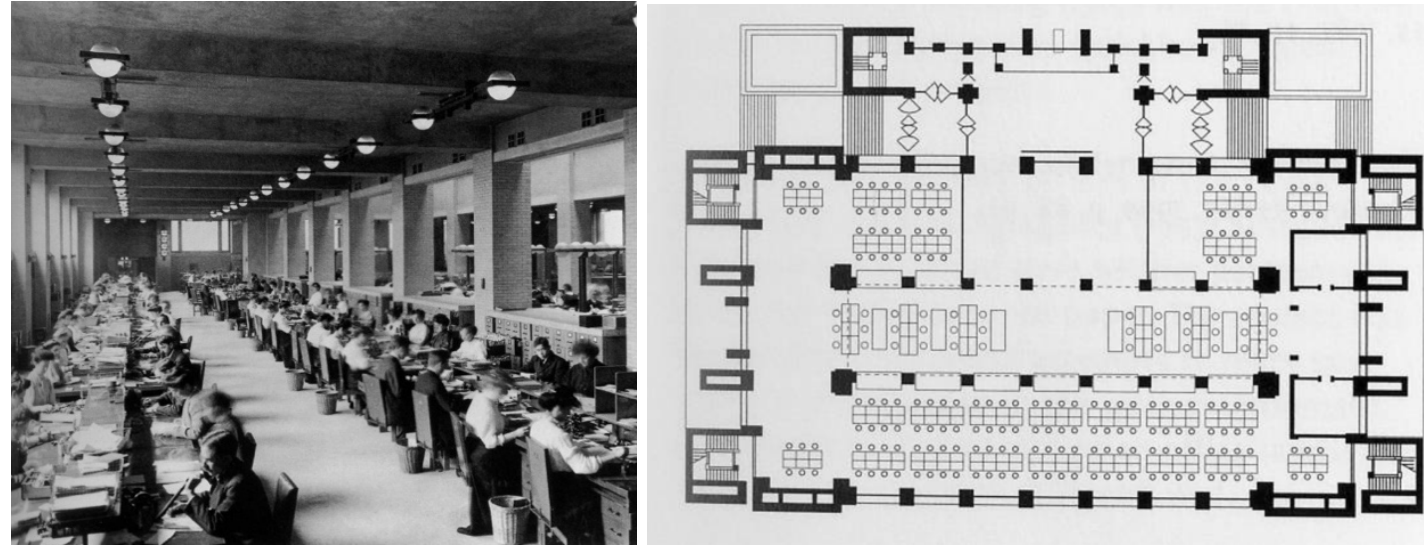

Şekil 5. Larkin Yönetim Binası çalışma havuzu görünüşü (solda) çalışma katı planı (sağda), New York, 1906 (Url-2).

Finansal kaygılarla ortaya çıkmış olan; ofis çalışanlarının kontrolünün arttırılarak daha hızlı çalışmalarının sağlanmasıyla ve daha küçük birim alana daha fazla çalışan sığdırılmasıyla işverenin karını arttırmayı hedefleyen bu yaklaşım, her ne kadar eleştiriye açık olsa da, ofis yapılarının kurgusu üzerinde önemli bir gelişmeye sebep olmuş; " açık ofis" kavramının doğmasını sağlamıştır.

İkinci Dünya Savaşı (1939-1945) sonrasında gelişen teknolojilerin yeni ürünleri olarak kullanılmaya başlanan cam giydirme cepheler ve mekanik iklimlendirme sistemleri yüksek ofis yapılarının tasarımında yeni bir dönem başlatmıştır. Uluslararası stildeki yüksek ofis yapıları yalın biçimlerdir. Süslemesiz, hafif, cam ve/veya başka bir malzemeyle giydirilmiş; yapının sahip olduğu düşey etkiyi vurgulayacak giydirme cephelere sahiptir. Bu yapılar genellikle kolonlar üzerinde yükseltilmiş, çatıları ise teras 
çatı olarak çözümlenmiştir. Bu monolitik "kutular"ın formları yapı strüktürünün limitleri, kiralanabilir alanların en yüksek büyüklükte tutulması ve plan alanı derinliğinin arttırılması kaygısı ile biçimlenmiştir (Armstrong, 1995, s. 4-5).

New York'ta bulunan tasarımı Skidmore, Owings and Merrill firması tarafından gerçekleştirilen Lever House Binası (1952) ve Ludwig Mies van der Rohe ve Philip Johnson tarafından tasarımı gerçekleştirilen Seagram Binası (1958) dönemin yapılarının en önemli örneklerinden ikisini oluşturur. Camdan ve çelikten oluşan giydirme cepheye ve prizmatik forma sahip bu minimalist yapılar kendilerinden önceki 70 yıl boyunca yapılmış süslemeci yüksek yapı tasarımlarının popülerliklerini kaybetmesine neden olmuştur (Şekil 6). Giydirme cepheler yeni mimari stilin etkisinin yanında camın taşa göre daha ucuz olması, iç mekana gün ışığı geçişini kolaylaştırması ve kiralanabilir alanlarda artış sağlaması sebepleriyle de yatırımcılar tarafından sıkça tercih edilmiştir (Ascher, 2011, s. 16-17).
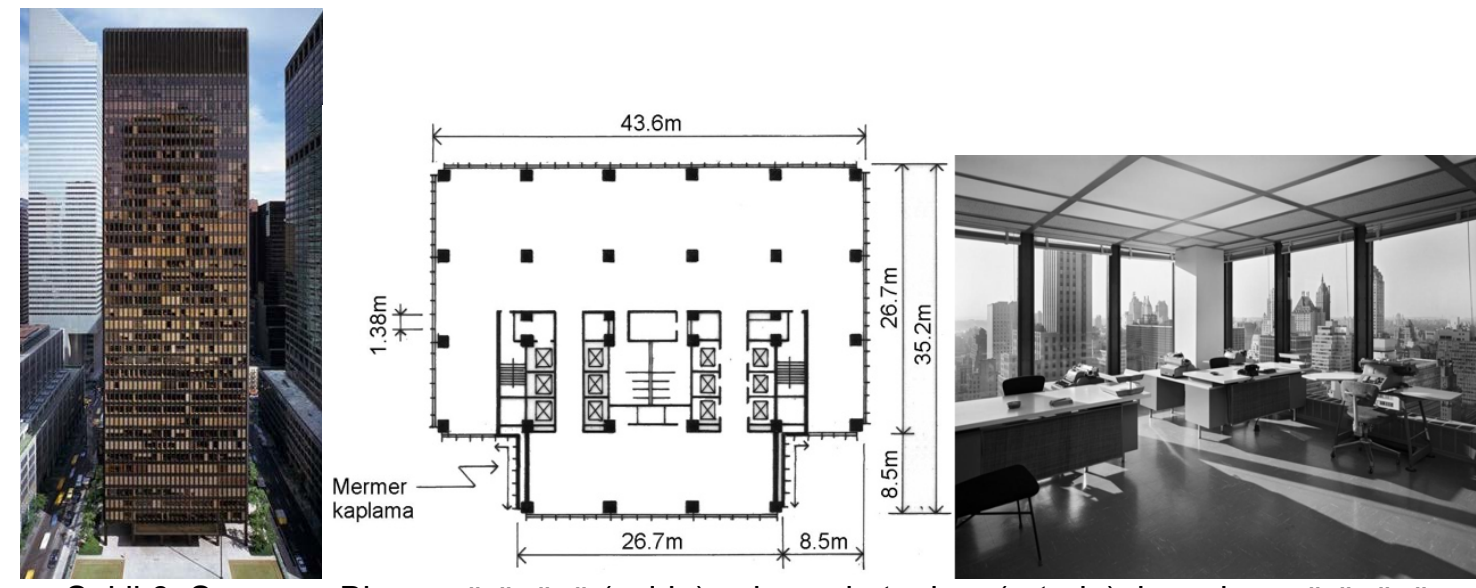

Şekil 6. Seagram Binası görünüşü (solda) çalışma katı planı (ortada), iç mekan görünüşü (sağda) (Url-3), New York, 1958.

Bir yanda teknolojik gelişmeler, öte yanda kullanıcıların performansını arttırma isteği ile 1950 'lerin sonlarında "Bürolandschaft-Office landscape" olarak isimlendirilen yeni bir planlama yaklaşımı ortaya çıkmıştır. Bu planlama yaklaşımına göre, kurumun tüm çalışanları unvanına bakılmaksızın tek bir mekân içinde konumlandırııılar. Çalışma alanları arasında herhangi bir sabit bölücü kullanılmamakta, çalışma alanları herhangi bir geometrik kaygı gözetilmeksizin, çalışanlar arasındaki ilişki esas alınarak kurgulanmaktadır (Şekil 7). Yaklaşımın temel amacı çalışanlar arasında iletişimin ve böylece çalışma veriminin arttırılmasıdır (Piotrowski \& Rogers, 1999, s. 8-9). 


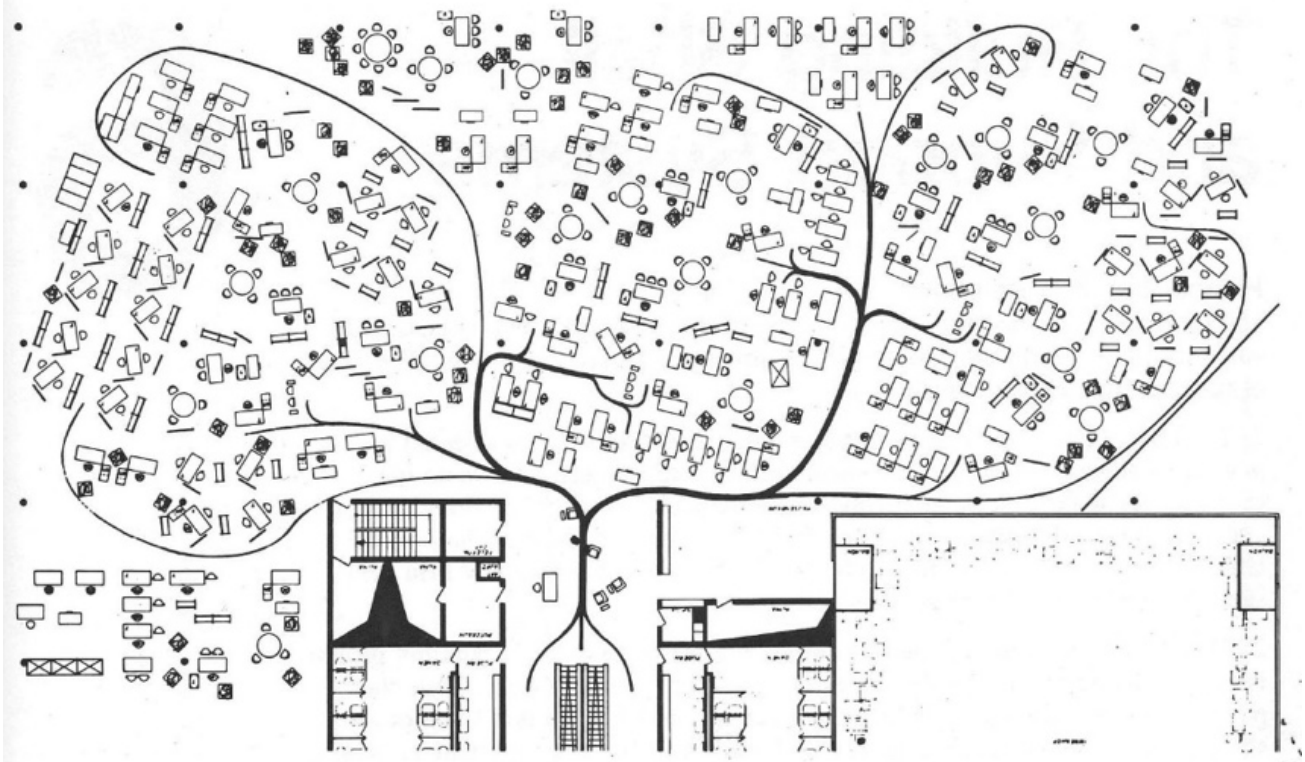

Şekil 7. Landscape ofis planlaması (Piotrowski \& Rogers, 1999, s. 53).

Ofislerin bu yeni çalışma düzeninin bir gerekliliği olarak kolonsuz çalışma alanları elde etmek yüksek yapı tasarımcılarının öncelikli hedeflerinden biri haline gelmiştir. Bu noktadan hareketle, 1960lı yıllar yüksek yapıların strüktür sistemlerinde önemli gelişmelere sahne olmuştur (Moon, 2005).

\subsection{Ekonomik ve teknolojik faktörlerin strüktürel gelişime etkisi}

Ekonomik ve teknolojik kaygılar yüksek ofis yapılarının sadece mimari tasarımlarının gelişimlerinde değil aynı zamanda, strüktürel gelişimlerinde de etkili olmuştur. Daha önce de bahsedildiği gibi Yüksek Yapılar ve Kentsel Yerleşimler Konseyi (CTBUH) tarafından ilk yüksek yapı olarak kabul edilen Home Insurance Binası dökme ve dövme demir kolonlara, dökme demir kirişlere ve yatay yüklere (rüzgâr yükleri) karşı stabilite sağlayan kalın yığma duvarlara sahiptir (Craighead, 2009). Yapının yapımından itibaren yapı iskeletinde kagir malzemelere göre daha hafif olan ve bu sayede hem planda daha az yer kaplayan, hem de cephede daha geniş açıklıklara olanak veren malzemeler olan demir ve çelik yüksek ofis yapılarında sıkça kullanılmaya başlamıştır. Bununla beraber, o yıllarda yüksek yapılarda yatay yüklere dayanım halen cephede masif kagir duvarlarla sağlanıyor, bu da cephe açıklıklarının kısıtlanmasına neden oluyor, iç mekanların yeterli ışık almasına engel oluyordu (Deplazes, 2005). Mühendisler bu sorunu çözmek için köprülerde yatay yüklere karşı kullanılan elemanları yüksek yapılara da uygulamışlardır. Yatay yüklere karşı dayanım sağlayacak olan bu yapı elemanları yapılarda "çelik çaprazlar" olarak isimlendirilmiştir (Leslie, 2013, s. 78-100).

Chicago'da bulunan Burnham ve Root tarafından tasarlanarak 1893 yılında yapımı tamamlanan 16 katı ıonadnock Binası hem çelik yapı teknolojilerinin yüksek yapılarda uygulanmaya başlamasının ilk örneklerinden biri olması hem de, zemin katta $1.83 \mathrm{~m}$ kalınlığa ulaşan tuğla yığma duvarlarıyla kagir sistemlerin yüksek yapılardaki kullanımının sınırlarına işaret etmesi sebepleriyle kagir yığma taşıyıcı sisteme sahip yüksek yapılar ve rijit çelik çerçeve sistemlerine sahip yüksek yapılar arasında bir geçiş yapısı örneğidir (Şekil 8) (Leslie, 2013, s. 26-31). 

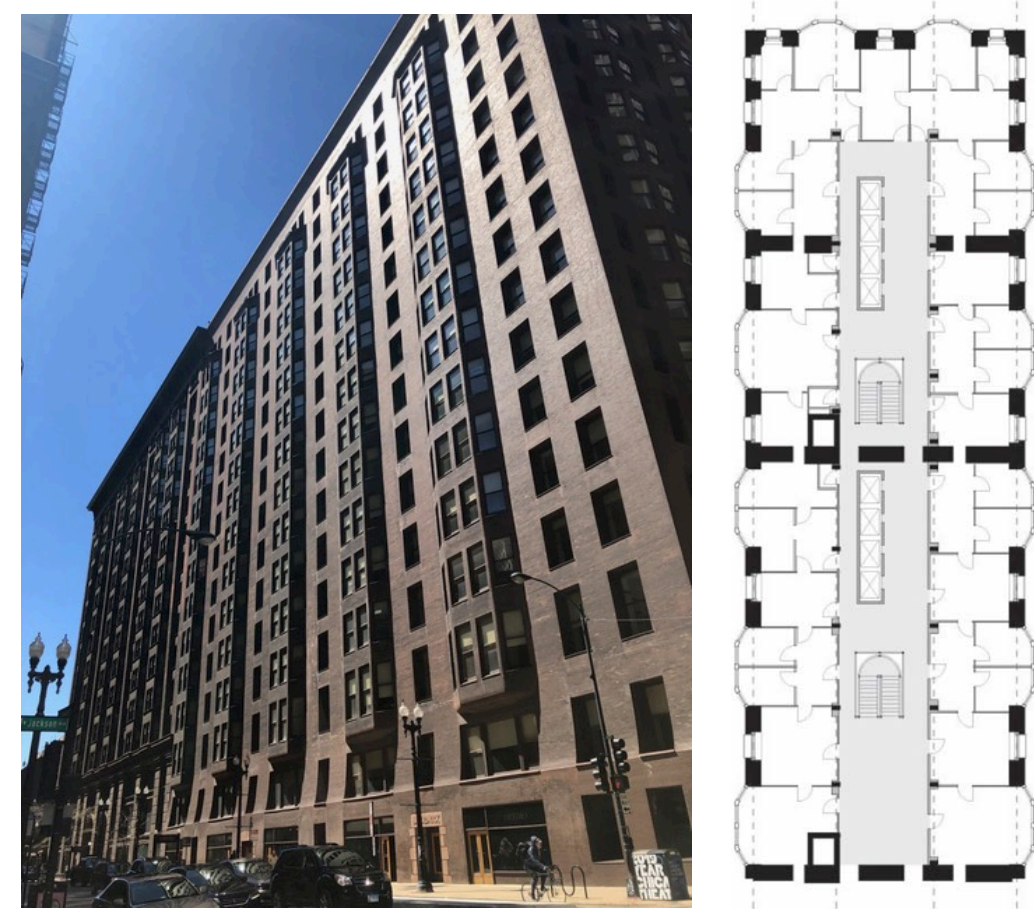

Şekil 8. Monadnock Binası görünüşü (solda) (foto:yazarlar), tipik ofis katı planı (Willis, 1995, s. 55) (sağda) (Chicago, 1893).

Monadnock Binasının yapımından sonra, yatay stabilite sağlayan kagir duvarlar yerlerini çelik çaprazlara bırakmış; bu çaprazlar, çelik kolonlar ve kirişler ile birlikte rijit çerçeveli çelik sistemleri oluşturmuştur. Tasarımı Burnham and Root mimarlık firması tarafından gerçekleştirilen Masonic Temple (1892, Chicago), Old Colony (1895, Chicago) ve Tasarımı yine Burnham and Root mimarlık firması tarafından gerçekleştirilen Reliance (1895, Chicago) Binaları çelik çaprazlar, kolonlar ve kirişlerden oluşan rijit çerçeveli çelik sistemlerin ilk örnekleridir (Şekil 9) (Leslie, 2013, s. 78-100).
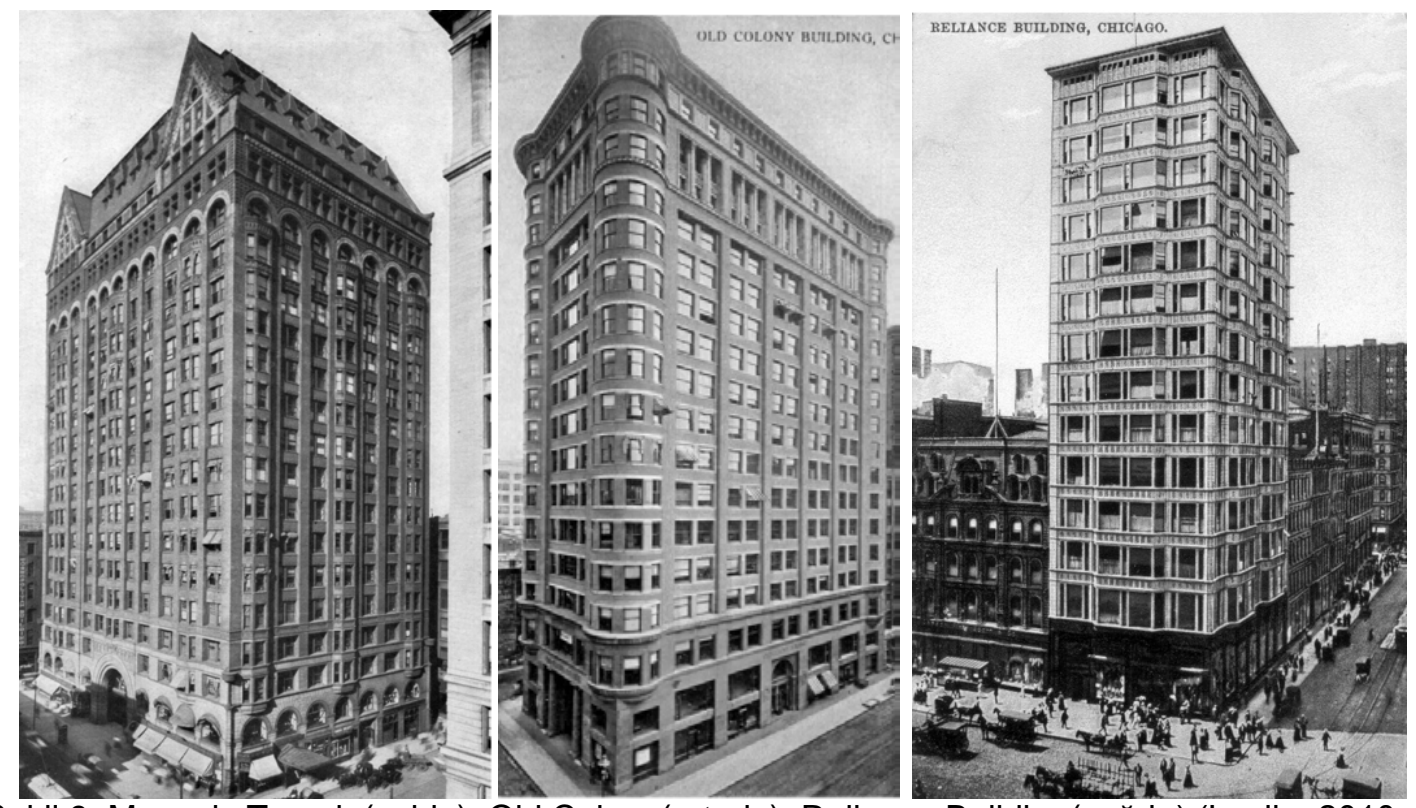

Şekil 9. Masonic Temple(solda), Old Colony(ortada), Reliance Building(sağda) (Leslie, 2010, s. 242-253). 
Rijit çerçeveli çelik sistemler incelendiğinde, bu sistemlerin, daha fazla doğal ışığa sahip olduğu için daha yüksek gelir getiren mekanlar elde etmek amacıyla geliştirilmiş oldukları görülmektedir (Moon, 2005).

1960’ı yıllara kadar yüksek ofis yapılarında rijit çerçeveli çelik sistemler sıkça kullanılmıştır. Her biri yapıldığı dönemde yükseklik rekoru kıran tasarımı H. Craig Severance önderliğinde bir ekip tarafından gerçekleştirilen 40 Wall Street Binası (1930, New York), tasarımı William van Alen tarafından gerçekleştirilen Chrysler Binası (1930, New York) ve tasarımı Shreve, Lamb \& Harmon firması tarafından gerçekleştirilen Empire State Binası (1931, New York) gibi günümüzde ikonik etkileri olan yüksek ofis yapıları rijit çerçeveli çelik sistemler ile yapılmıştır (Şekil 10).

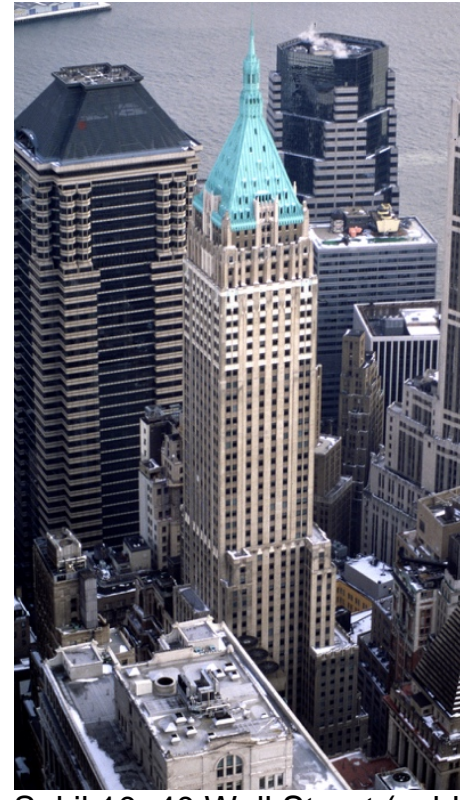

Şekil 10. 40 Wall Street (solda)
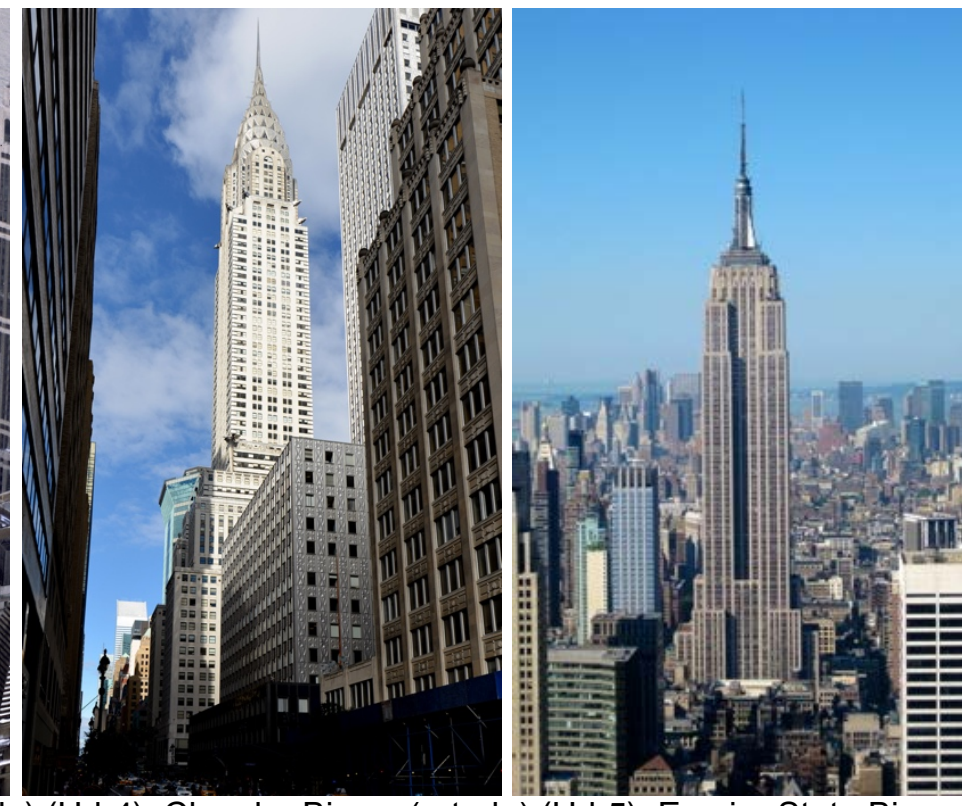

) (Url-5), Empire State Binas

(sağda) (Url-6)

1960’lı yıllarda teknolojik alanda önemli gelişmeler olmuştur. Mevcut teknolojilerin 2. Dünya Savaşı sırasında geliştirilmesiyle 20. yy'nin ilk yarısında bilgisayar kullanımına ilişkin ilk adımlar atılmıştır. 1950'lerde sayısal teknolojiler hayatın birçok alanında etkili olmuştur. Bilgisayar kullanımı ve sayısal teknolojilerdeki bu gelişmeler yapıya etki eden yüklerin 3 boyutlu analizini mümkün kılmış ve taşıyıcı sistem teknolojisinin bir adım daha gelişmesini sağlamıştır. F. Khan tarafından geliştirilen ve yerçekimi yükleri ile yatay yüklere dış cephede yer alan tek bir sistem ile karşı koyma prensibine dayanan "tübüler sistem"ler 60 kattan yüksek yapılarda kullanılmaya başlanmıştır (Khan, 1965, s. 2-15). Bu taşıyıcı sistem türünün ortaya çıkmasındaki temel etken, açık ofis planlamasına sahip olması istenen yüksek ofis yapılarında rijit çerçeveli taşıyıcı sistemlerin bir gereği olarak bulunan kolonların iç mekanlarda istenen esnekliğin sağlanmasının önünde ciddi bir engel oluşturması ve rijit çerçeveli çelik sistemlerin 60 katın üzerindeki yapılarda iktisadi/ekonomik olmamasıdır.

Çaprazlı tüple taşınan Skidmore, Owings and Merrill tarafından tasarımı gerçekleştirilen John Hancock Binası (1969, 344m), Minoru Yamasaki tarafından tasarımı gerçekleştirilen Dünya Ticaret Merkezi Kuleleri (1972, çerçeveli tüp, 526m) ve Bruce Graham tasarımı gerçekleştirilen Sears Kulesi olarak da bilinen Willis Kulesi (1974, demet tüp, 527m) bu dönemde tübüler sistem ile inşa edilmiş yapılara örnek oluşturmaktadır. Şekil 11'de bu yapılar ve ofis katı plan şemaları görülmektedir. Bu kat 
planları, tübüler sistem kullanımının ofis mekanlarının düzenlenmesinde sağladığı plan serbestliğini açıkça ifade etmektedir.

1960'lı yıllardan başlayarak 1990'lı yıllara kadar sıkça kullanılan tübüler sistemler yüksek ofis yapılarının planlarında serbestlik ve esneklik sağlamış olsa da, Dünya Ticaret Merkezi Kuleleri ve Willis Kulesinde (Sears Kulesi) olduğu gibi cephedeki sık aralıklı kolonlar veya John Hancock Binasında olduğu gibi büyük boyutlardaki çaprazlar kullanıcıların gün ışığını ve manzarasını engelleme sorununu çıkarmıştır. Bu etkiler adı geçen binaların iç mekanlarındaki görüntülerden açıkça anlaşılmaktadır (Şekil 11).

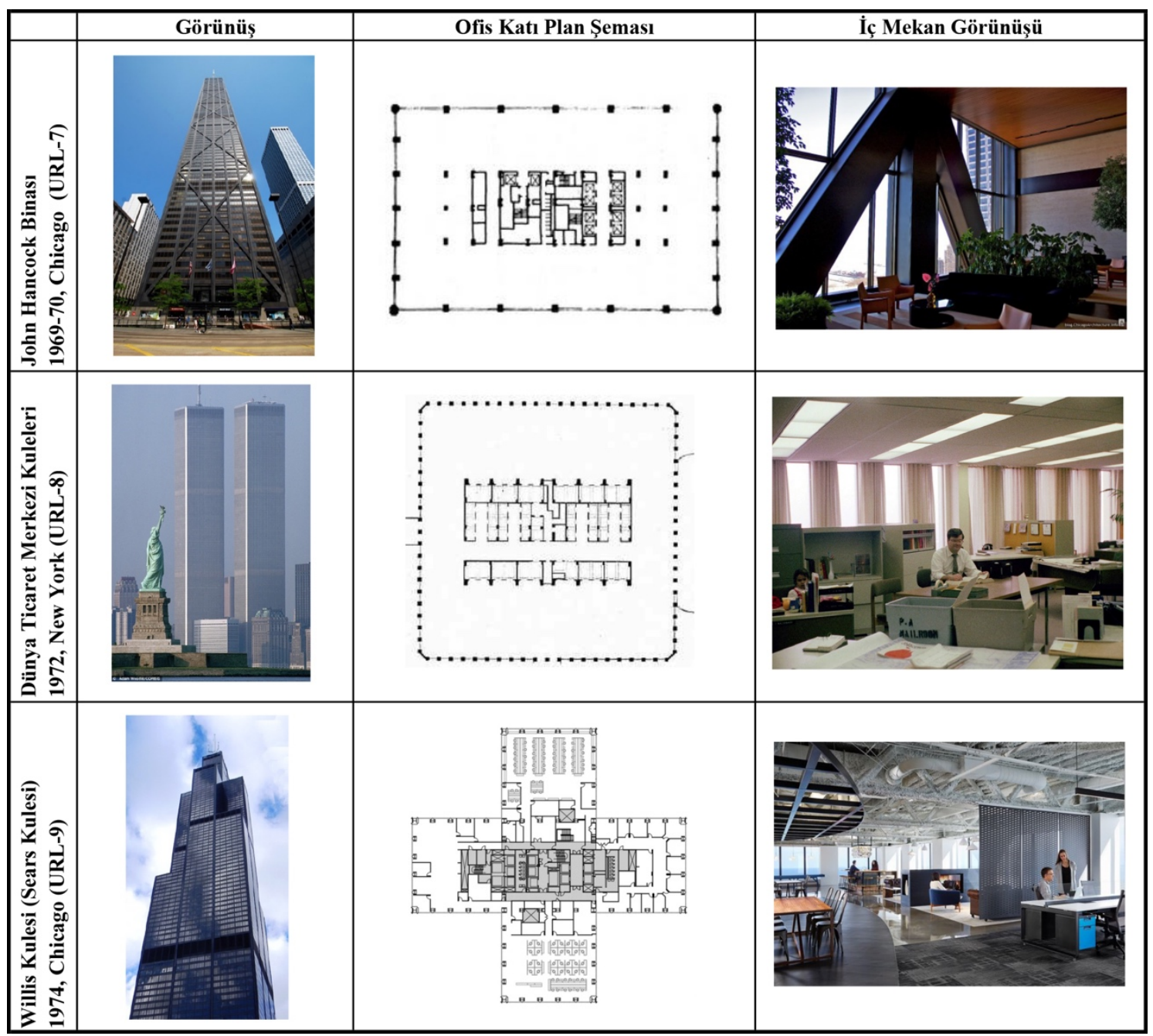

Şekil 11. Tübüler sisteme sahip yapılar ve ofis katı plan şemaları (Url-7; Url-8, 2019; Url-9).

1970'lerin ortalarında yaşanan petrol krizi yüksek yapıların gelişiminde duraklamaya neden olmuş, yaklaşık 20 yıl yüksek yapıların strüktürlerinde herhangi bir gelişme yaşanmamıştır (Ascher, 2011, s. 18-20). 1990'larda bilgisayar teknolojilerinde ve malzeme biliminde yaşanan gelişmelerin sağladığı imkanlarla yüksek yapılarda cephe ve form esnekliğini sınırlayan tübüler sistemlere bir cevap olarak daha esnek tasarımlara imkan sağlayacak çekirdek ve yatay kafes kirişli sistemler, mega çerçeveler, diyagrid sistemler yüksek yapılarda yeni bir dönemi başlatmıştır (Kowalczyk, Sinn, \& Kilmister, 1994, s. 1). 
Çekirdek ve yatay kafesli kirişli sistemler, yapının dış kabuğunda bulunan az sayıdaki büyük kolonun, kat yüksekliğinde yatay kafes kirişlerle belli yükseklik aralıklarıyla yapı çekirdeğinin kesme duvarlarına bağlanmasıyla oluşturulmaktadır (Choi, Ho, Joseph, \& Mathias, 2012, pp. 14-15). Yatay kafes kirişli sistemlerin kullanımı ile yapı çepherindeki taşıyıcı çerçeve rijit bağlantılar içermek zorunda olmadığından taşıyıcı sistem maliyeti azalmıştır. Zemin tarafından uygulanan kaldırma gücünde azalma meydana geldiği için temel maliyeti düşmektedir. Mega kolonlar ve kuşaklar ile cephede ve iç mekanlarda esneklik sağlanmıştır (Lame, 2008).

Yapımı 1999 senesinde tamamlanan, Çin'in Şanghay kentinde bulunan, 88 katlı ve 421 m yüksekliğindeki Jin Mao Binası çekirdek ve kat yüksekliğindeki yatay kafes kirişli sistemlerin etkin bir örneğidir (Şekil 12) (Choi, Ho, Joseph, \& Mathias, 2012, s. 60-61).

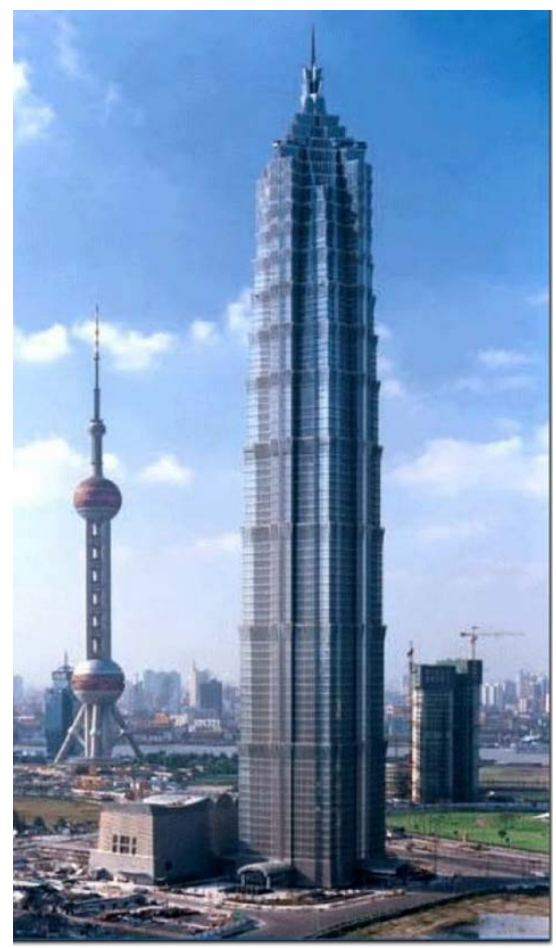

Şekil 12. Jin Mao Binası görünüşü (Tasarım: Adrian Smith- Skidmore, Owings and Merrill, 1999, Şanghay-Çin) (Choi, Ho, Joseph, \& Mathias, 2012, s. 60).

Yapı sekizgen biçimli betonarme çekirdeğe sahiptir. Bu betonarme çekirdek iki kat yüksekliğindeki yatay kafes kirişler ile yapının çeperindeki sekiz kompozit mega kolona bağlanmaktadır (Şekil 13). Konik biçimdeki kolonlar yapının özel formunu meydana getirmektedir. Çelik döşeme kirişleri, ikincil çelik kolonlar, kompozit döşeme levhalar ve beton döşemeler Jin Mao Binasının beton ile çeliğin bir arada kullanılmasıyla oluşturulan kompozit strüktürlerin önemli bir örneği olmasını sağlamaktadır (Choi, Ho, Joseph, \& Mathias, 2012, s. 60). 

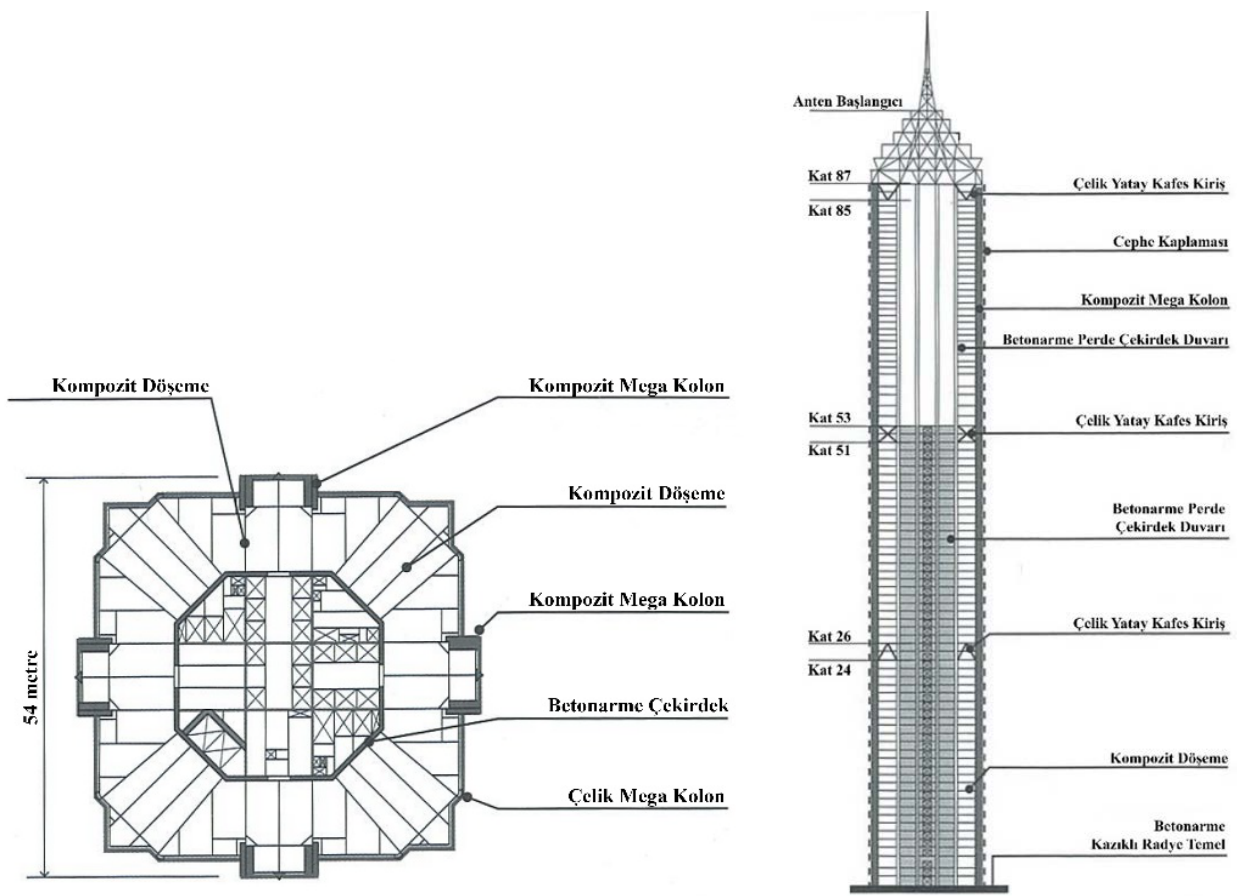

Şekil 13. Jin Mao Binası ofis katı planı (solda), şematik kesiti (sağda) (1999, Şangay, Çin) (Choi, Ho, Joseph, \& Mathias, 2012, s. 60).

Jin Mao Binası, çekirdek ve kat yüksekliğinde yatay kafes kirişli sistemlere örnek olmasının yanında, mega çerçeveli yapıların da ilk örneklerinden birini oluşturmaktadır. 20. yy'nin sonlarında kullanılmaya başlayan mega çerçeveler, çekirdek ve kat yüksekliğinde yatay kafes kirişli sistemlere benzer şekilde iç mekanın doğal olarak aydınlanmasına imkan veren, alan verimliliğinin sağlandığı ve yapı içinde esneklik ve modülerliğin mümkün olduğu strüktürler elde edilmesini sağlamakta olup, mega kolonlar, kirişler, makaslar, yatay kafes kirişler, kuşaklar gibi taşıyıcı sistem elemanlarının bir arada kullanılması ile oluşturulmaktadır. Yatay yüklere mümkün olan en hafif strüktürlerle dayanım sağlamayı hedeflemektedir (Sev \& Özgen, 2009).

21. yy, mekânsal gereksinimlerin yanında prestij kaygısının yüksek ofis yapılarının gelişimi üzerinde etkili olduğu bir dönemdir. Bu dönemde, daha yükseğe ulaşmak, daha yeni bir teknolojiye sahip olmak, daha organik bir forma sahip olmak gibi kaygılar yüksek ofis yapılarının mali getirilerini yükselten ve gelişimlerini ivmelendiren ekonomik faktörler olmuşlardır (Ali \& Al-Kodmany, 2012, s. 384-423; Moon, 2011, s. 1343-1350). "Diyagrid sistemler" serbest formlara imkan tanımaları, cephe ve planda esneklik sağlamaları, strüktürel hafiflikleri sebepleriyle 21. yy'nin strüktürel intiyaçlarına cevap verecek niteliklere sahip bir başka strüktür türü olarak kullanılmaya başlamıştır.

Diyagrid sistem, yapının çeperinde bulunan diyagonal strüktürel elemanlar ile yatay ve düşey yüklere stabilite sağlama fikrinden ortaya çıkmıştır. Bu sistemde düşey kolonlar ve yatay kirişler olmaksızın, eksenel yük aktarmakta daha başarılı bir davranış gösteren diyagonal elemanlar kullanılmaktadır (Boake, 2016, s. 293). Londra'da 30 st. Mary Axe (2004), New York'ta Hearst Kulesi (2006), Tokyo'da bulunan Mode Gauken Cacoon Kulesi (2008) ve Calgary'de The Bow Binası (2010) diyagrid sistemlerin başarılı örneklerindendir (Şekil 14) (Al-Kodmany \& Ali, 2016, s. 275; Boake, 2016, s. 293-304). 

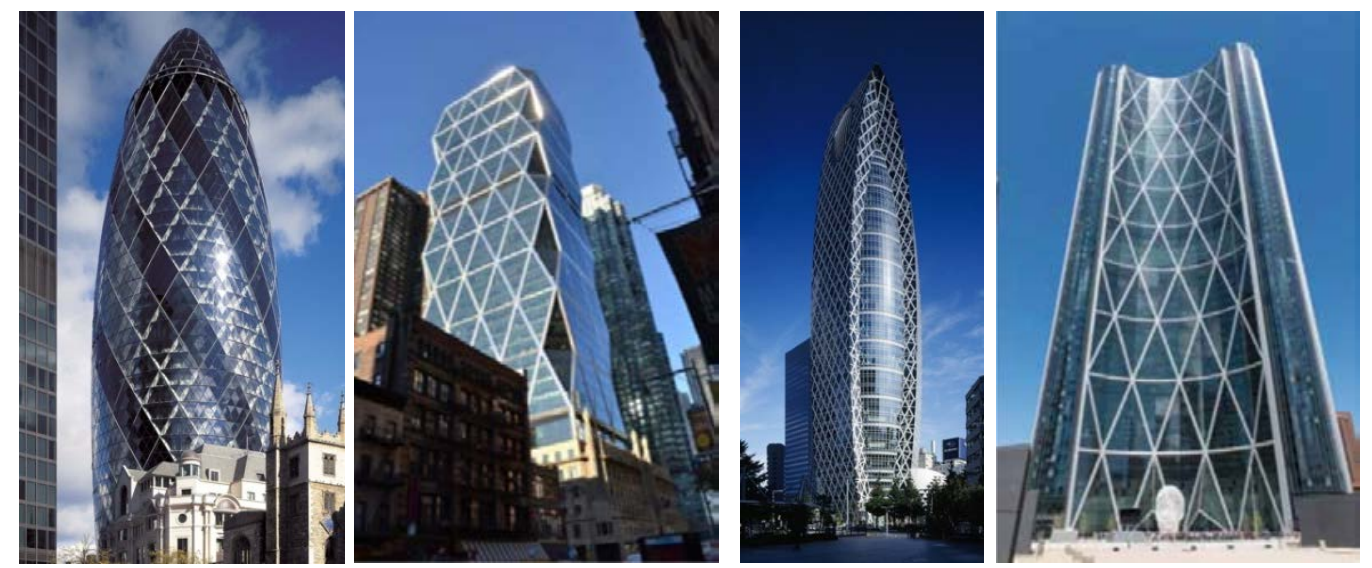

Şekil 14. Sırasıyla 30 St. Mary Axe (Tasarım:Norman Foster ve Ken Shuttleworth, Londra, 2004), Hearst Kulesi (Tasarım:Norman Foster, New York, 2006), Mode Gauken Cacoon Kulesi (Tasarım: Paul Noritaka Tange, Tokyo, 2008) (Url-10) ve Bow Binası (Tasarım:

Foster\&Partners, Zeidler Ortaklığı, Calgary, 2010) (Barnes \& Hendricks, 2013, s. 13).

30 St. Mary Axe Binası diyagrid taşıyıcı sisteme sahip olmasının yanında 1970'lerde yaşanan enerji krizlerinden günümüze mimarlık literatüründe güncel bir araştırma konusu haline gelen "sürdürülebilirlik" ve "enerji etkin tasarım" kavramlarına da yer vermesi ve doğal iklimlendirme stratejilerinin etkin olarak kullanılması bakımından çağımızın yüksek yapı tasarım anlayışını büyük ölçüde yansıtmaktadır (Rahimian, 2016, s. 263-270).

Yapının dairesel formunun merkezinde düşey dolaşım elemanları, tuvaletler ve diğer servis mekânlarını bulunduran çekirdeklerin; planın çeperlerinde ise altı üçgen biçimli atriyumun ve ofislerin konumlandırılığı görülür. Doğal havalandırma sağlanması için yapının etrafında spiral olarak dönerek devam eden atriyumlar konumlandırılmıştır. Diyagrid taşıyıcı sistem ile sağlanan plan esnekliği ve atriyumlar ile yapının iç mekânlarının doğal hava ve gün ışığı alması sağlanmış, aynı zamanda kolonsuz iç mekânlar elde edilmiştir (Wood \& Salib, 2013, s. 84-92) (Şekil 15).

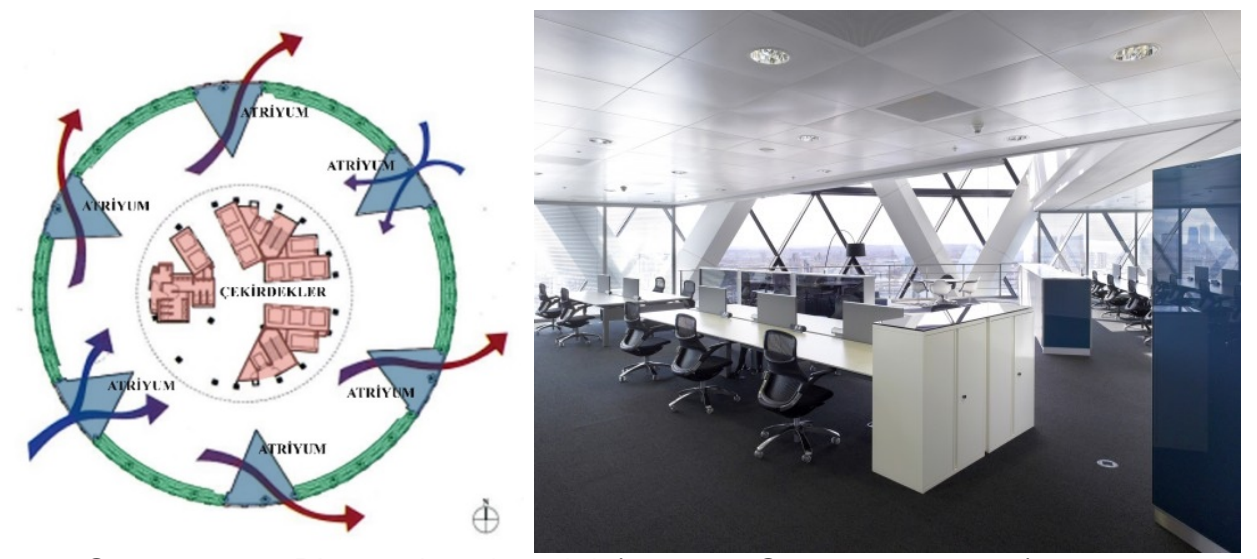

Şekil 15. 30 St. Mary Axe Binası planı (sağda) (Wood \& Salib, 2013, s. 86), iç mekan görünüşü (solda) (Url-11).

Günümüzde Dünya'daki en yüksek yapı olma unvanını Birleşik Arap Emirliklerinin Dubai kentinde bulunan ve yapımı 2010 senesinde tamamlanan 828 m yüksekliğindeki 165 katıı Burj Khalifa taşımaktadır (Şekil 16). Burj Khalifa yeni bir strüktür türü olarak kabul edilen "payandalı çekirdek" olarak isimlendirilen bir taşıyıcı sisteme sahiptir (Ali \& Al-Kodmany, 2012, s. 404-406). Bu taşıyıcı sistemin tasarımı ve yapımı ise bilgisayar ve malzeme teknolojilerinde yaşanan gelişmeler ile mümkün olmuştur (Abdelrazaq, 2011, s. 18-23). 


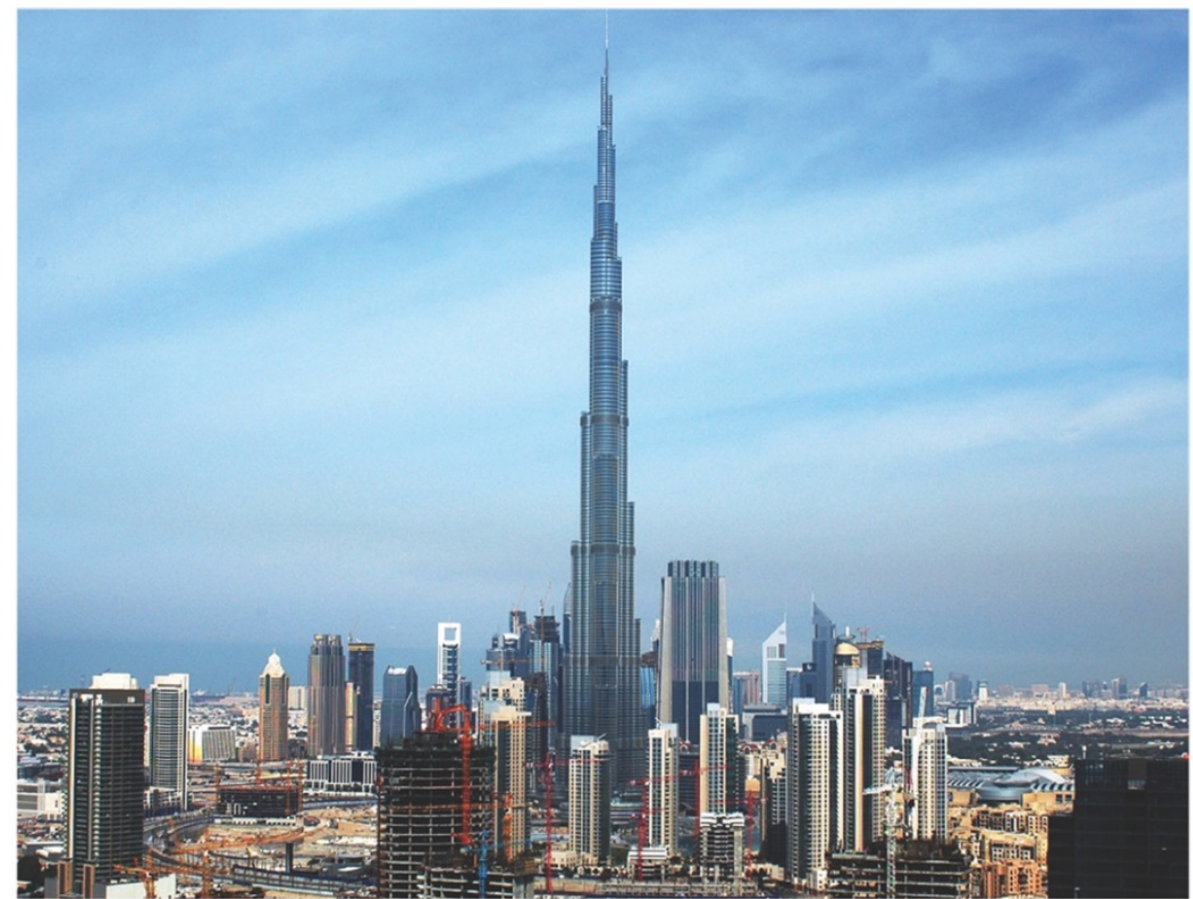

Şekil 16. Burj Khalifa görünüşü (Tasarım: Adrian Smith- Skidmore, Owings \& Merrill, DubaiBAE, 2010) (Aldred, 2010, s. 67).

Payandalı çekirdek sistem altıgen biçiminde bir çekirdek ve bu çekirdeğe bağlanan 3 kanattan oluşmaktadır (Şekil 17). Bir kanata yatay yük geldiğinde bu yük çekirdek aracılığıyla diğer iki kanada aktarılır. Sistem adını bu çalışma prensibinden almaktadır (Ali \& Al-Kodmany, 2012, s. 398; Abdelrazaq, 2011, s. 18-23). Yapı 156. kata kadar betonarme üzerinde ise strüktürel çelik olacak şekilde tasarlanmıştır.

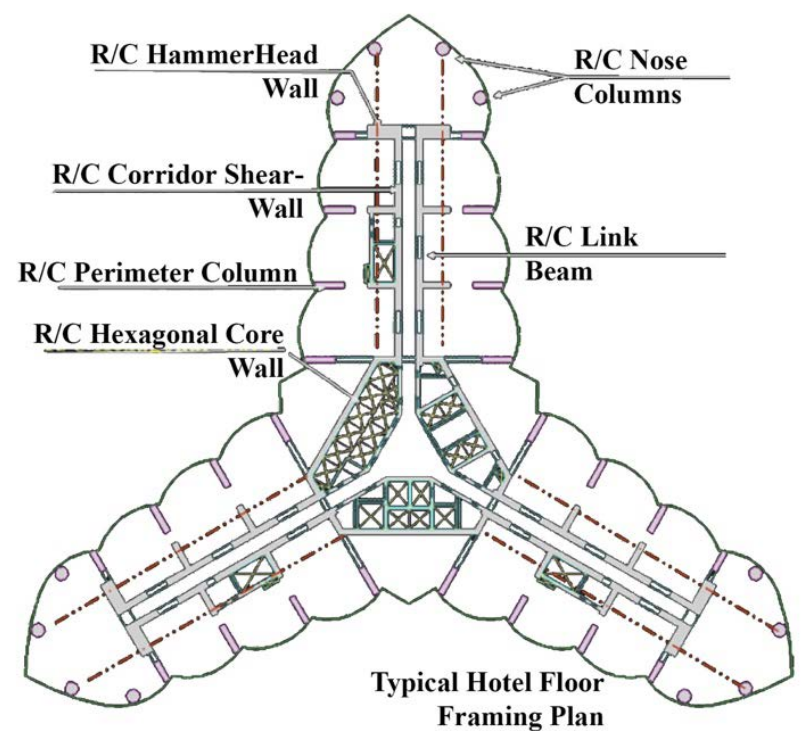

Şekil 17. Burj Khalifa plan şeması (Abdelrazaq, 2011, s. 20).

20. yy'nin sonlarında yapıya etkiyen yüklerin bilgisayarlarda sayısal analizi mümkün olsa da, farklı programların birbirleri ile bütünleşik olarak kullanılması güçlük oluşturmuştur. Burj Khalifa'nın tasarımı sırasında ise planlama, tasarım ve inşa süreçlerinin tümünde gerçek zamanlı taşıyıcı sistem izleme (SHM) programı kullanılmıştır. Bu sayede yapının betonarme temel kazıklarındaki yük dağılımları, temel 
tasarımı ve yapımı, çekirdek duvarları, yapının göstereceği yatay ötelenme ve düşey elemanlardaki basınç ve direnç birarada bilgisayar teknolojilerinin yardımı ile değerlendirilmiştir. Ayrıca, yapıya geçici ve kalıcı gerçek zamanlı izleme programları kurularak kullanılan malzeme ve sistemlerin rüzgar ve sismik yükler altındaki etkileri izlenmiştir ve izlenmektedir (Abdelrazaq, 2011, s. 18-23).

\section{DEĞERLENDIRME VE SONUÇ}

Ekonomi ve teknoloji karşılıklı olarak birbirini besleyen iki temel unsurdur. Bir yüksek ofis yapısının tasarımında ve yapımında bu iki unsur önemli rol oynar. Yapıların yükselebilmesi için hem yeterli finans hem de yeterli teknolojiye sahip olunması gereklidir. Bununla beraber, yüksek ofis yapıları da yatırımcılarına gelir ve prestij sağlamakta etkin olan yapı tipolojileridir. Başka bir deyişle, yüksek ofis yapıları yatırımcılarına sağladıkları gelir, yüksek ofis yapılarının yapımı için gerekli olan finans ve yüksek ofis yapılarının yapımında gerekli teknoloji arasında çok yönlü bir ilişki bulunmaktadır.

19. yy sonlarından başlayarak 20. yy sonlarına kadar olan yaklaşık 100 yıl boyunca daha fazla kar sağlama güdüsü yapı tasarımcılarını daha aydınlık, daha büyük ve daha arzulanır nitelikte mekanların tasarımı için arayışa itmiştir. Bu arayış yüksek ofis yapılarının mimari ve strüktürel gelişiminde önemli rol oynamıştır.

Demir-çelik profillerin yapılarda kullanılması, asansörün icadı, giydirme cephelerin kullanılması, yapay iklimlendirme servislerinin gelişimi ve son olarak yapıya etkileyen yüklerin sayısal ortamda üç boyutlu olarak analiz edilebilmesi yüksek ofis yapılarının daha fazla yükselmesi ve daha nitelikli mekanlara sahip olması için gerekli teknolojik alt yapıyı sağlamıştır.

Bu yapı tipolojisinin kısa tarihi incelendiğinde yüksek ofis yapılarının gelişimi üzerinde etkili olan bir diğer unsurun toplumsal değişim-dönüşüm olduğu görülür. Toplumsal değişim yüksek ofis yapılarının gelişimi üzerindeki etkisini, kent yaşamına ilginin artması sonucu kent merkezlerinin yoğunlaşmasıyla ve 19. yy başlarında kentlerde çoğunluğu oluşturan "işçi sınıfının" yerlerini sermaye birikimi ile kurulan banka ve sigorta şirketlerinde çalışan "beyaz yakalı sınıfına" bırakmasıyla göstermiştir. Ek olarak, bu beyaz yakalı çalışanlar grubunun daha etkin ve verimli çalıştırılması isteği-kar güdüsünün bir başka ifadesi- Taylorizmin doğmasını ve yüksek ofis yapılarının mekanlarının taylorist yaklaşımın gerekliliklerine cevap verebilecek nitelikte tasarlanmasını sağlamıştır. Günümüzde de sıkça kullanılan açık ofis tasarımının temelleri bu ilkeye dayanmaktadır.

Gelişen teknolojilere bağlı olarak kullanım niteliği yüksek mekanlar elde etmek bir tasarım engeli oluşturmasa da yüksek ofis yapılarının tasarımında ekonomik ve teknolojik faktörlerin etkisi sürmektedir. Bu etkiler yüksek ofis yapılarının daha yeni/yenilikçi teknolojilere sahip olması ve daha yükseğe ulaşabilmesi yoluyla bulunduğu ülkeye ve yatırımcısına daha fazla prestij sağlaması isteği ile ifade bulmaktadır.

Çağımızda, Dünya'nın içinde bulunduğu küresel ısınma, iklim değişikliği gibi güncel problemler nüfusu gün geçtikçe artan kentlerde vazgeçilmez birer yapı tipolojisi haline gelen yüksek yapıların tasarımında enerjinin etkin kullanımını dolayısıyla "enerji etkin tasarım", "enerji verimliliği" kavramlarını önemli birer tasarım gerekliliği ve problemi haline getirmiş olup, yüksek (ofis) yapılarının mimari ve strüktürel tasarımı üzerinde etkili bir diğer etmeni oluşturmaktadır. 


\section{KAYNAKLAR}

Abdelrazaq, Ahmad, "Validating the dinamics of the Burj Khalifa", CTBUH Journal, 2011, CTBUH, s. 18-23.

Aldred, James, "Burj Khalifa-a new high for high-performance concrete", Proceedings of the institution of civil engineers, GHD Pty Ltd., Sydney-Australia 2010, s. 66-73.

Ali, M. Mir ve Al-Kodmany, Kheir, "Tall Buildings and Urban Habitat of the 21st Century: A Global Perspective", Buildings, 2012, s. 384-423.

Al-Kodmany, Kheir ve Ali, M. Mir, "An Overview of Structural \& Aesthetic Developments in Tall Buildings Using Exterior Bracing \& Diagrid Systems", International Journal of High-Rise Buildings, 2016, 5(4), s. 271-291.

Ascher, Kate, The Heights: Anatomy of a Skyscraper, The Penguin Press, New York 2011.

Barnes, James ve Hendricks, Jonathan, "Case Study: The Bow, Calgary", CTBUH Journal, CTBUH, 2013, 3, s. 12-19.

Armstrong Paul J., Architecture of Tall Buildings, McGraw-Hill Inc., ABD 1995.

Boake, Terry Meyer, "The Emergence of the Diagrid - It's All About the Node", International Journal of High-Rise Buildings, CTBUH, 2016, 5(4), s. 293-304.

Choi, Hi Sun; Ho, Goman; Joseph, Leonard ve Mathias, Neville, Outrigger Design for High-Rise Buildings, Routledge, New York 2012.

Craighead, Geoff, High-Rise Security and Fire Life Safety, Elseiver, Burlington 2009.

Deplazes, Andrea, Constructing Architecture: Materials Processes Structures a Handbook, Birkhauser Verlag AG., Berlin 2005.

Hascher, Rainer; Jeska, Simone ve Klauck, Birgit, A Design Manual: Office Buildings, Birkhauser, Berlin 2002.

Khan, Fazlur, "Design of high-rise buildings", A Symposium on Steel, Chicago 1965.

Kowalczyk, Ryszard; Sinn, Robert; Kilmister, Max B., Structural Systems for Tall Buildings. McGraw-Hill Inc., New York, 1994.

Lame, Ali, Optimization of Outrigger Structures, Yüksek Kisans Tezi. Massachusetts Institute of Technology, Boston 2008.

Larson, Gerald R.; Geraniotis, Roula Mouroudellis, "Toward a Better Understanding of the Evolution of the Iron Skeleton Frame in Chicago", Journal of the Society of Architectural Historians, 1987, 46(1), s. 39-48.

Leslie, Thomas, "Built Like Bridges: Iron, Steel, and Rivets in the Nineteenth-century Skyscraper", Journal of the Society of Architectural Historians, 2010, s. 234-261. 
Leslie, Thomas, Chicago Skyscrapers 1871-1934, University of Illinois Press, Chicago 2013.

Leslie, Thomas, "The Monadnock Building, Technically Reconsidered", CTBUH Journal, 2013, s. 26-31.

Moon, Kyoung Sun, Diagrid Structures for Complex-Shaped Tall Buildings, Procedia Engineering, 2011, 14, s. 1343-1350.

Moon, Kyoung Sun, Dynamic Interrelationship Between Technology and Architecture in Tall Buildings, Doktora Tezi, Massachusetts Institute of Technology, Boston 2005.

Piotrowski, Christine. M.; Rogers, Elizabeth A., Designing Commercial Interiors, John Wiley \& Sons, Inc., New York 1999.

Rahimian, Ahmad, "Stability of Diagrid Structures", International Journal of High-Rise Buildings, CTBUH, 2016, 5(4), s. 263-270.

Sev, Ayşin, Innovations in Tall Building Design nd Technology: From Balloon Frame to the Megastructures, Scholars' Press, Saarbrücken-Germany 2015.

Sev, Ayşin ve Özgen, Aydan, "Space efficiency in high-rise office buildings" Metu Journal of Faculty of Architecture, İstanbul 2009, 2, s. 69-89.

Short, Michael J., Planning for Tall Buildings, Routledge, New York 2012.

Taylor, F. Winslow., The Principles of Scientific Management, Harper\&Brothers Publishers, New York and London 1911.

Trabucco, Dario, "Historical Evolution of the Service Core", CTBUH Journal, 2010, CTBUH, s. 42-47.

Url-1. 05 Aralık 2019 tarihinde https://chicagology.com/skyscrapers/skyscrapers038/ adresinden alındı.

Url-2. 05 Ekim 2017 tarihinde https://en.wikiarquitectura.com/building/larkin-building/ adresinden alındı.

Url-3. 05 Aralık 2019 tarihinde https://www.archaic-mag.com/magazine/tag/ adresinden alındı.

Url-4. 05 Aralık 2019 tarihinde http://www.skyscrapercenter.com/building/the-trumpbuilding/619 adresinden alındı.

Url-5. 05 Aralık 2019 tarihinde http://www.skyscrapercenter.com/building/chryslerbuilding/422 adresinden alındı.

Url-6. 05 Aralık 2019 tarihinde https://tr.wikipedia.org/wiki/Empire_State_Binası adresinden alındı.

Url-7. 05 Aralık 2019 tarihinde https://www.e-architect.co.uk/chicago/john-hancockcenter adresinden alındı. 
Url-8. 05 Aralık 2019 tarihinde www.dailymail.co.uk/news/article-2365931/LarrySilverstein-World-Trade-Center-owner-trying-sue-airlines-billions-9-11-attacks.html adresinden alındı.

Url-9. 05 Aralık 2019 tarihinde http://khan.princeton.edu/khanSears.html adresinden alındı.

Url-10. 05 Aralık 2019 tarihinde https://www.archdaily.com/139167/mode-gakuencocoon-tower-tange-associates adresinden alındı.

Url-11. 05 Aralık 2019 tarihinde www.fosterandpartners.com/projects/30-st-mary-axe adresinden alındı.

Willis, Carol, Form Follows Finance, Princeton Architectural Press, New York 1995.

Wood, Antony ve Salib, Ruba, Natural Ventilation in High-Rise Office Buildings, Routledge, Londra 2013. 